Document downloaded from:

http://hdl.handle.net/10251/62456

This paper must be cited as:

Anquela Julián, AB.; Martín Furones, AE.; Berné Valero, JL.; Padin Devesa, J. (2013). GPS and GLONASS Static and Kinematic PPP results. Journal of Surveying Engineering. 139(1):47-58. doi:10.1061/(ASCE)SU.1943-5428.0000091.

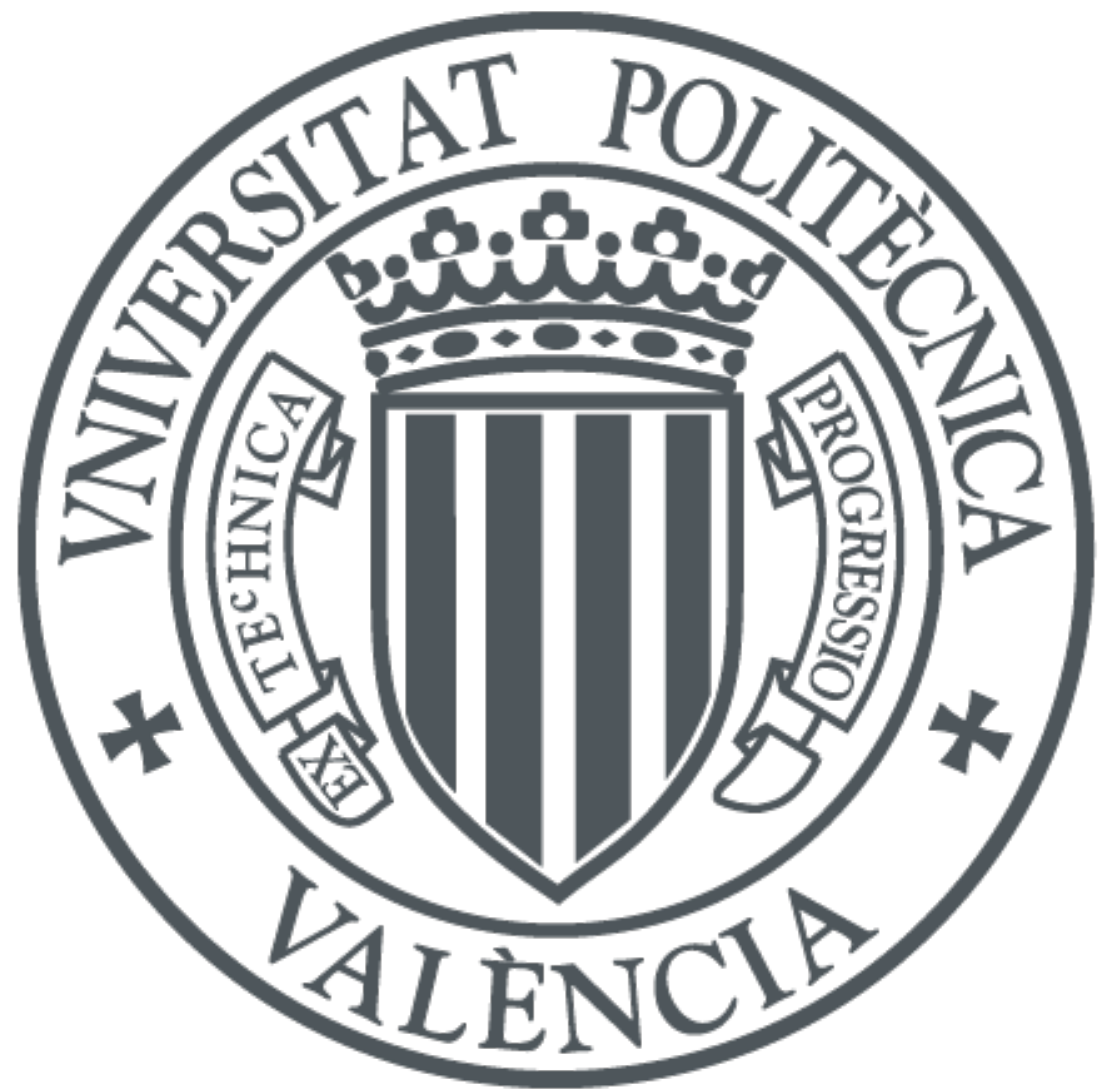

The final publication is available at

http://dx.doi.org/10.1061/(ASCE)SU.1943-5428.0000091

Copyright American Society of Civil Engineers

Additional Information 


\title{
GPS + GLONASS Static and Kinematic PPP Results
}

\author{
A. B. Anquela ; A. Martín ${ }^{2}$; J. L. Berné ${ }^{3}$ and J. Padín ${ }^{4}$
}

3

4

\begin{abstract}
Precise point positioning (PPP) involves observations from a single global navigation satellite system (GNSS) receiver and benefits of satellite orbit and clock products obtained from the global infrastructure of permanent stations. PPP avoids the expense and logistic difficulties of deploying a network of GNSS receivers around survey areas in isolated places, such as the arctic or less populated areas. Potential accuracies are at the centimeter level for static applications and at the subdecimeter level for kinematic applications. Static and kinematic PPP based on the processing of global positioning system (GPS) observations is limited by the number of visible satellites, which is often insufficient for urban or mountain applications, or it can be partially obstructed or present multipath effects. Even if a number of GPS satellites are available, the accuracy and reliability can still be affected by poor satellite geometry. One possible way of increasing satellite signal availability and positioning reliability is to integrate GPS and global navigation satellite system (GLONASS) observations. This case study deals with the possibilities of combining GPS and GLONASS dual-frequency measurements on the static and kinematic PPP solution to reduce the convergence time and improve the accuracy of the solution. The results show that the addition of the GLONASS constellation does not always improve the convergence of static PPP; the kinematic results (car and walk trajectories) present better accuracy from the GPS + GLONASS solution rather than the GPS-only solution. The MagicGNSS software was used in processing of all observations. DOI: 10.1061/(ASCE)SU.19435428.0000091. (C) 2013 American Society of Civil Engineers.
\end{abstract}

CE Database subject headings: Global positioning systems; Case studies; Surveys; Satellites.

Author keywords: GNSS; Precise point positioning; GLONASS.

\section{Introduction}

Precise point positioning (PPP) has attracted much interest in recent years and has provided an alternative to precise relative processing because of its possibilities as a reliable absolute positioning technique. PPP can provide subdecimeter-to-centimeter positioning accuracy without the use of base stations (e.g., Zumberge et al. 1997; Kouba and Héroux 2001; Gao and Shen 2002). PPP employs carrier phase and pseudorange observations in processing algorithms, where precise satellite orbits and clock information are used instead of broadcast information. Thus, PPP has the benefit of using the most accurate postmission or near-real-time information as published by the International Global Navigation Satellite System (GNSS) Service (IGS).

PPP was first developed for use in static applications (e.g., Zumberge et al. 1997) and has been studied extensively in recent years (Kouba and Héroux 2001; Gao and Shen 2001; Bisnath et al.

${ }^{1}$ Dept. of Cartographic Engineering, Geodesy and Photogrammetry, Polytechnic Univ. of Valencia, ClCamino de Vera s/n, Valencia 46022, Spain. E-mail: aemartin@upvnet.upv.es

${ }^{2}$ Dept. of Cartographic Engineering, Geodesy and Photogrammetry, Polytechnic Univ. of Valencia, ClCamino de Vera s/n, Valencia 46022, Spain (corresponding author). E-mail: anquela@cgf.upv.es

${ }^{3}$ Dept. of Cartographic Engineering, Geodesy and Photogrammetry, Polytechnic Univ. of Valencia, ClCamino de Vera s/n, Valencia 46022, Spain. E-mail: jlberne@cgf.upv.es

${ }^{4}$ Dept. of Cartographic Engineering, Geodesy and Photogrammetry, Polytechnic Univ. of Valencia, ClCamino de Vera s/n, Valencia 46022, Spain. E-mail: jpadin@cgf.upv.es

Note. This manuscript was submitted on February 1, 2012; approved on June 5, 2012; published online on August 11, 2012. Discussion period open until July 1, 2013; separate discussions must be submitted for individual papers. This paper is part of the Journal of Surveying Engineering, Vol. 139, No. 1, February 1, 2013. CASCE, ISSN 0733-9453/2013/1-1-12/ $\$ 25.00$.
2002; Colombo et al. 2004; Chen et al. 2009; Geng et al. 2010). With the development of final, near-real-time or real-time satellite orbit and clock products, kinematic PPP is being increasingly used in research and applications. Kinematic PPP is used in airborne and marine applications overseas; in sparsely populated regions such as mountains, prairies, or desert regions; and in areas where the GNSS infrastructure is poorly developed, such as Greenland and northern Canada (Chen 2004; Héroux et al. 2004; Jensen and Ovstedal 2008).

Even with more than 30 satellites in the global positioning system (GPS) constellation, there are situations where the satellite signal may be partially obstructed (urban positioning in general, mountains, open-pit mines, or heavy tree cover), which in turn affect the availability and reliability of the PPP solution. A possible method to ensuring a continuous solution is the use of the full range of satellites from both the GPS and global navigation satellite system (GLONASS) systems.

Since the beginning of 2010, the revitalized Russian constellation GLONASS has 21 operational satellites; thus, a PPP solution with GPS + GLONASS can take advantage of extended satellite availability. As a result, a major improvement in PPP can be expected in terms of shorter convergence time and increased accuracy. In Cai and Gao (2007), four processing sessions, each with 3-h data from three IGS stations (HERT, GOPE, and YARR), were analyzed with the conclusion that no significant convergence improvement was found, indicating that this improvement is dependent on improvements in the satellite geometry for position determination. In the same study, $12 \mathrm{~h}$ of observations from the HERT station were analyzed with the conclusion that GLONASS did not have a significant impact on the positioning coordinates and errors for GPS + GLONASS solutions compared with the GPS-only solutions. A kinematic measurement campaign was performed by Hesselbarth and Wanninger (2008), in which they concluded that adding GLONASS observations to GPS reduces convergence times by a factor of 1.5-2.5 for underdecimeter accuracies; however, the 


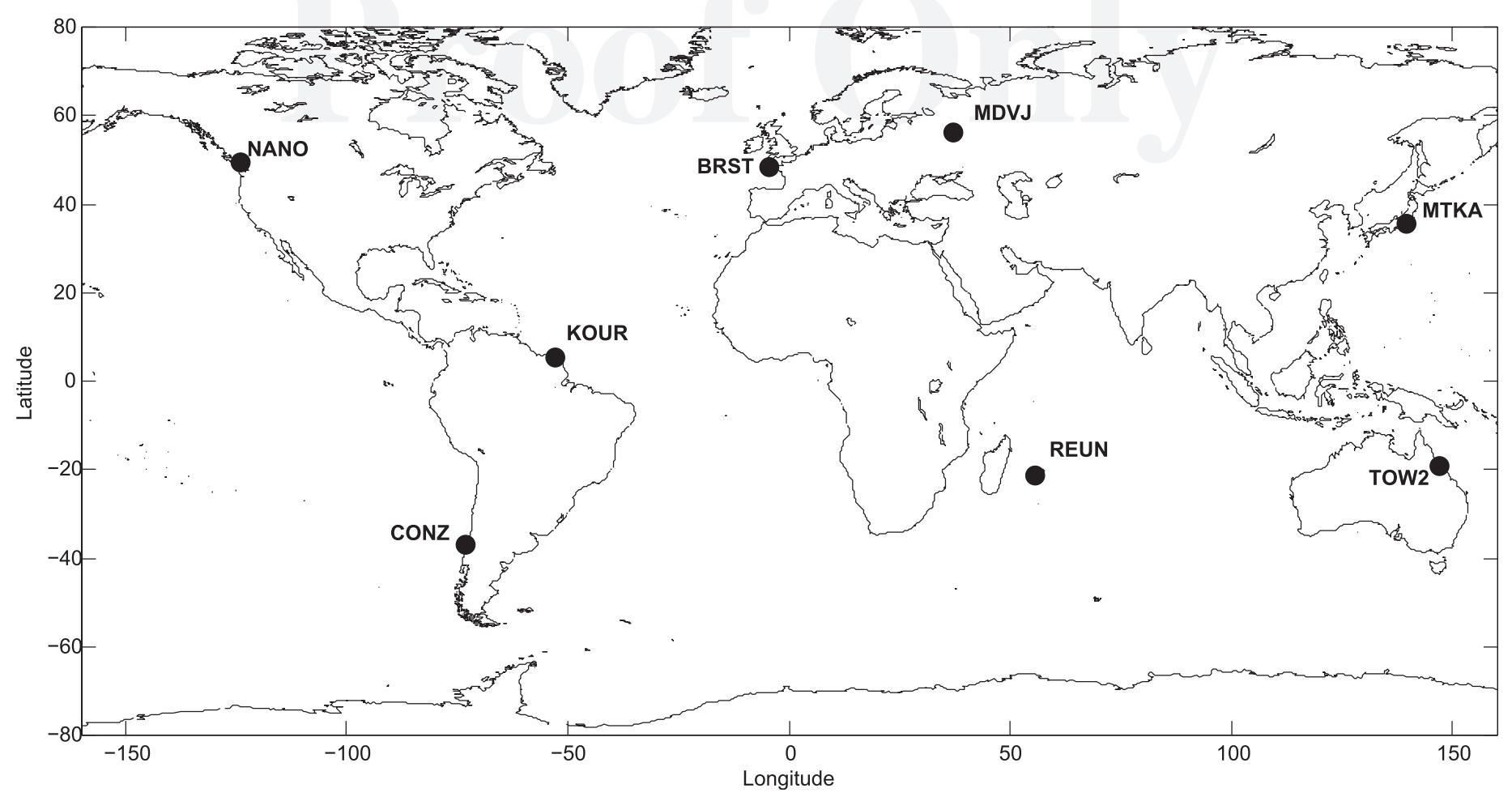

Fig. 1. Location of the eight IGS stations used in the study; coastline file from the NGDC (2010)

Table 1. Receivers, Antennas, Recorded Sample Interval, and Location in Latitude and Longitude for the IGS Permanent Sites

\begin{tabular}{|c|c|c|c|c|c|}
\hline Location & Receiver & Antenna & Sample interval (s) & Latitude $\left(^{\circ}\right)$ & Longitude $\left(^{\circ}\right)$ \\
\hline BRST (France) & LEICA GRX1200GGPRO & LEIAT504GG & 30 & $48^{\circ} 22^{\prime} 49^{\prime \prime}$ & $355^{\circ} 30^{\prime} 12^{\prime \prime}$ \\
\hline CONZ (Chile) & LEICA GRX1200GGPRO & TPSCR3_GGD & 30 & $-36^{\circ} 50^{\prime} 37^{\prime \prime}$ & $289^{\circ} 58^{\prime} 28^{\prime \prime}$ \\
\hline KOUR (French Guyana) & JPS LEGACY & ASH701946.3 & 30 & $5^{\circ} 15^{\prime} 7^{\prime \prime}$ & $307^{\circ} 11^{\prime} 38^{\prime \prime}$ \\
\hline MDVJ (Russia) & TPS NETG3 & JPSREGANT_DD_E & 30 & $56^{\circ} 1^{\prime} 17^{\prime \prime}$ & $37^{\circ} 12^{\prime} 52^{\prime \prime}$ \\
\hline MTKA (Japan) & ASHTECH Z18 & ASH701073.1 & 30 & $35^{\circ} 40^{\prime} 46^{\prime \prime}$ & $139^{\circ} 33^{\prime} 41^{\prime \prime}$ \\
\hline NANO (Canada) & LEICA GRX1200GGPRO & LEIAT504GG & 30 & $49^{\circ} 17^{\prime} 41^{\prime \prime}$ & $253^{\circ} 54^{\prime} 48^{\prime \prime}$ \\
\hline REUN (Reunion Island, France) & TRIMBLE NETR5 & TRM55971.00 & 30 & $-21^{\circ} 12^{\prime} 29^{\prime \prime}$ & $55^{\circ} 34^{\prime} 18^{\prime \prime}$ \\
\hline TOW2 (Australia) & LEICA GRX1200GGPRO & AOAD/M_T & 30 & $-19^{\circ} 16^{\prime} 09^{\prime \prime}$ & $147^{\circ} 03^{\prime} 20^{\prime \prime}$ \\
\hline
\end{tabular}

convergence time is not reduced for centimeter accuracy [accuracy is understood here as the difference between the PPP solution in comparison with the reference solution obtained from the differential kinematic carrier-phase processing of a short $(2.8 \mathrm{~km})$ baseline from a permanent reference station]. In Kjorsvik et al. (2009), 14 days of continuous observations at $1 \mathrm{~Hz}$ in a shuttle ferry traveling between Lauvvik and Oanes outside Stavanger, Norway, were processed in the kinematic PPP mode, where the contribution of GLONASS was found not to be significant. In Píriz et al. (2009), 20 control stations distributed worldwide were analyzed using 1 day of observation data. The RMS of the GPS-only and GLONASS-only position differences were approximately $5 \mathrm{~mm}$ in the horizontal components and above $1 \mathrm{~cm}$ in the vertical component; therefore, GPS + GLONASS positioning did not bring much benefit with respect to GPS only or GLONASS only. However, when only $1 \mathrm{~h}$ of static station data was used, the GPS + GLONASS solution was noticeably more accurate and considerably more robust than the GPS-only solution. In Melgard et al. (2010), one antenna at a fixed location for a 24-h period in Oslo, Norway, showed that the average convergence time improvement when adding GLONASS to GPS observations was about of $40 \%$ [the convergence criterion was considered as the time when the three-dimensional (3D) position arrives within $40 \mathrm{~cm}$ of the reference position and remains there for a minimum of $10 \mathrm{~min}$ ]. In Azab et al. (2011), five IGS reference stations were processed. The results showed that there was a significant improvement in the convergence and repeatability of the PPP GPS + GLONASS solution, especially in the first observation hour where positioning accuracy can be achieved with only $30 \mathrm{~min}$ of observation for the combined GPS + GLONASS solution, while it requires approximately $3 \mathrm{~h}$ for the GPS-only solution. A final reference, not for the PPP results but for relative baselines computed using GPS-only, GLONASS-only, and GPS + GLONASS constellations, is the recent study by Alcay et al. (2012), which concludes that there is no significant difference between the GPS-only and GPS + GLONASS results (for some baselines, repeatabilities are slightly better using GPS-only; for others, the repeatabilities improve when adding GLONASS and the GLONASS-only results are not as accurate as the GPS only and GPS + GLONASS).

Over the last few years, a number of organizations have developed online PPP GNSS processing services. These services provide PPP processing results to the user free of charge and with unlimited access, providing the opportunity to obtain high-precision coordinates in a recognized datum (e.g., ITRF). One of these online 7 


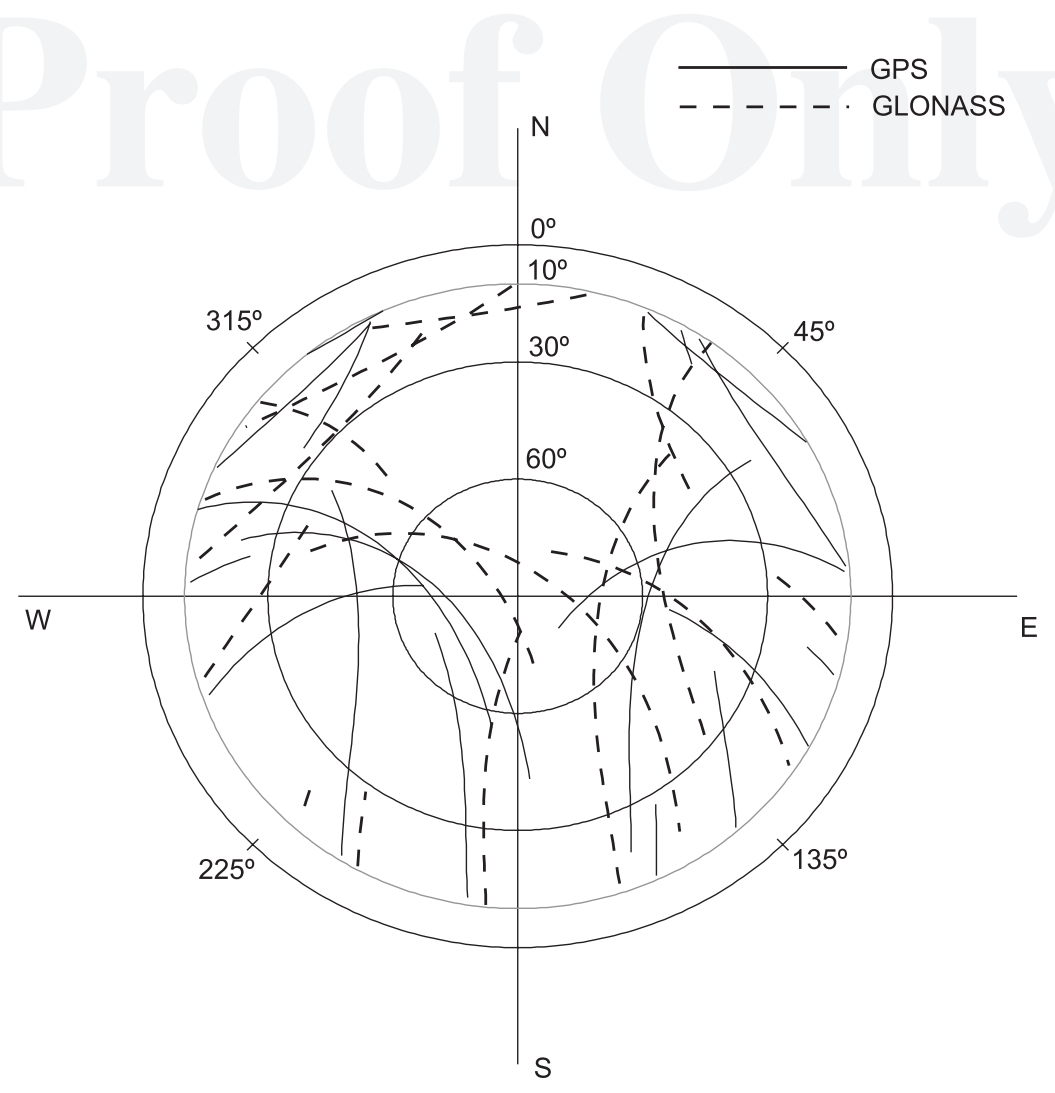

Fig. 2. Skyplot of the GPS and GLONASS constellations for the IGS MDVJ station (December 13, 2010)

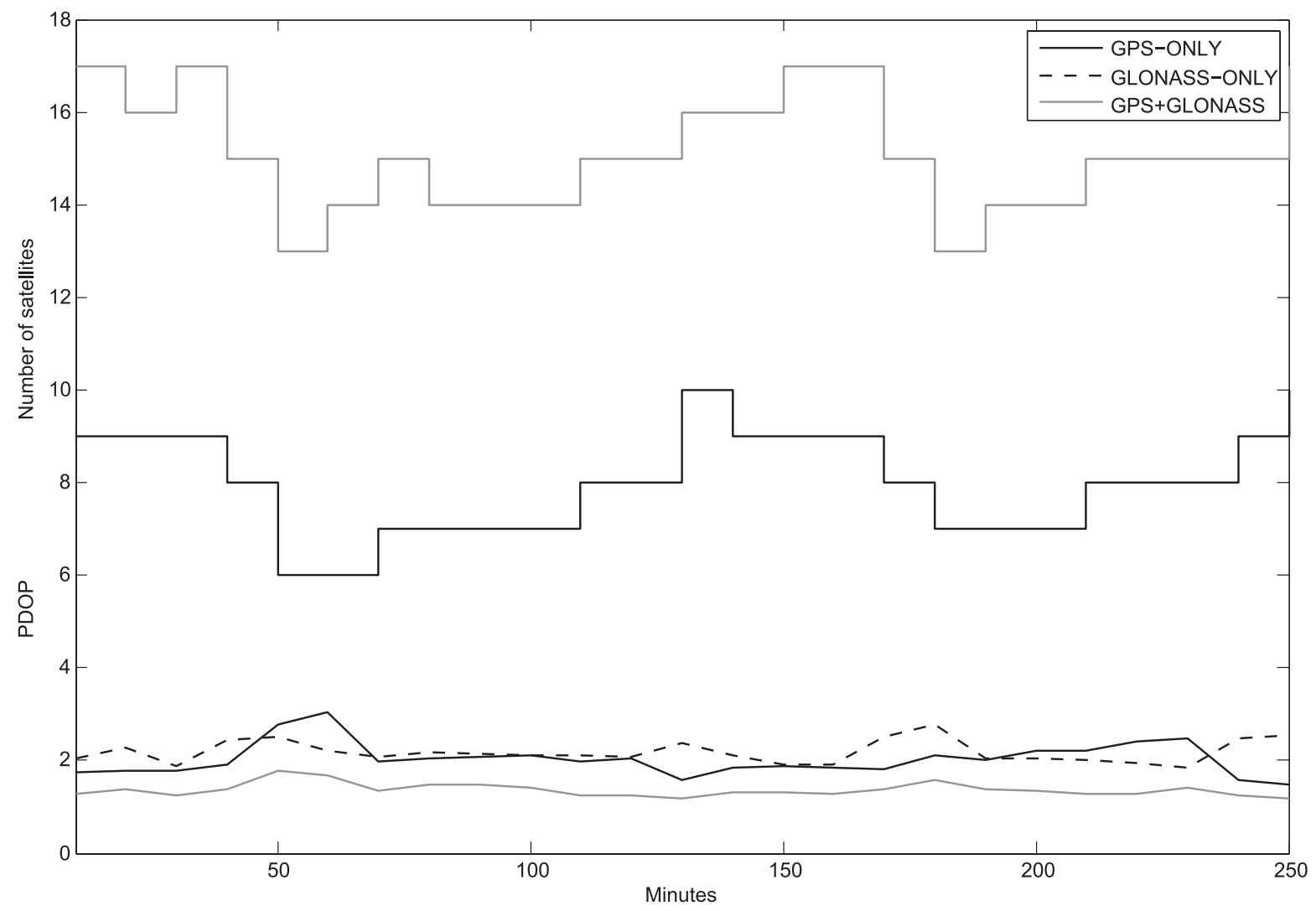

Fig. 3. PDOP and number of satellites for GPS-only, GLONASS-only, and GPS + GLONASS constellations for the IGS MDVJ station (December 13, 2010) 
software services is MagicGNSS, from GMV Aerospace and Defence (2010). This service (based on code and phase dual-frequency ionosphere-free combinations) was used in the processing of the observations used in this study. MagicGNSS consists of a batch leastsquares algorithm that minimizes measurement residuals and solves for GNSS satellite orbits and clock, phase ambiguities, tropospheric zenith delays, and also for station/receiver coordinates and clock in

Table 2. Mean RMS of Static PPP Measurements Residuals

\begin{tabular}{lcc}
\hline & $\begin{array}{c}\text { Mean RMS of code } \\
\text { residuals }(\mathrm{m})\end{array}$ & $\begin{array}{c}\text { Mean RMS of phase } \\
\text { residuals }(\mathrm{m})\end{array}$ \\
\hline GPS only & 0.260 & 0.012 \\
GLONASS only & 0.450 & 0.040 \\
GPS + GLONASS & 0.300 & 0.018 \\
\hline
\end{tabular}

Table 3. Mean Convergence Time

\begin{tabular}{|c|c|c|c|c|c|c|c|c|c|}
\hline \multirow{2}{*}{$\begin{array}{l}\text { Mean convergence } \\
\text { time to reach an } \\
\text { accuracy level of } \\
1 \text { or } 10 \mathrm{~cm}\end{array}$} & \multicolumn{3}{|c|}{ GPS only (min) } & \multicolumn{3}{|c|}{$\begin{array}{l}\text { GLONASS } \\
\text { only (min) }\end{array}$} & \multicolumn{3}{|c|}{$\begin{array}{l}\text { GPS }+ \\
\text { GLONASS } \\
\quad(\min )\end{array}$} \\
\hline & North & East & Up & North & East & Up & North & East & $\mathrm{U}_{\mathrm{p}}$ \\
\hline $1 \mathrm{~cm}$ & 70 & 95 & 100 & 130 & 150 & 160 & 60 & 77 & 85 \\
\hline $10 \mathrm{~cm}$ & 37.5 & 37.5 & 44.5 & 70 & 80 & 95 & 33 & 33 & 38 \\
\hline
\end{tabular}

PPP postprocess (Píriz et al. 2008). MagicGNSS has been able to process GLONASS observables since January 1, 2010; thus, the interchannel bias estimation can also be computed in the PPP postprocess (Píriz et al. 2009). Orbit and clock GPS and GLONASS files are generated internally twice per hour (on the hour and at the half hour), with a latency of 30 min from a network of GNSS stations distributed worldwide. GLONASS satellite clocks are postprocessed to be aligned to IGS time. These GLONASS orbit and clock files are used in any PPP postprocess solution; however, if IGS rapid or final files are available, they are used instead of the internal files for the GPS observations. Therefore, it is always possible to combine GPS and GLONASS in PPP postprocesses. A comparison of static and kinematic GPS-only PPP results of MagicGNSS software compared with other online software, such as the automatic precise positioning service (APPS), Canadian Spatial Reference System Online Global GPS Processing Service (CSRS-PPP), GPS analysis and position software (GAPS), or scientific software, such as BERNESE, can be found in Martín et al. $(2011,2012)$, where the good performance of MagicGNSS was demonstrated.

With the revitalization of the GLONASS satellite system, it has become worthwhile to investigate the usefulness of GLONASS on global positioning in terms of accuracy and precision. To investigate this for the PPP technique, this paper presents a complete analysis based on a case study using the GPS + GLONASS satellite constellation, both in static and kinematic modes; thus, it can be used to complete the previous references on the topic.
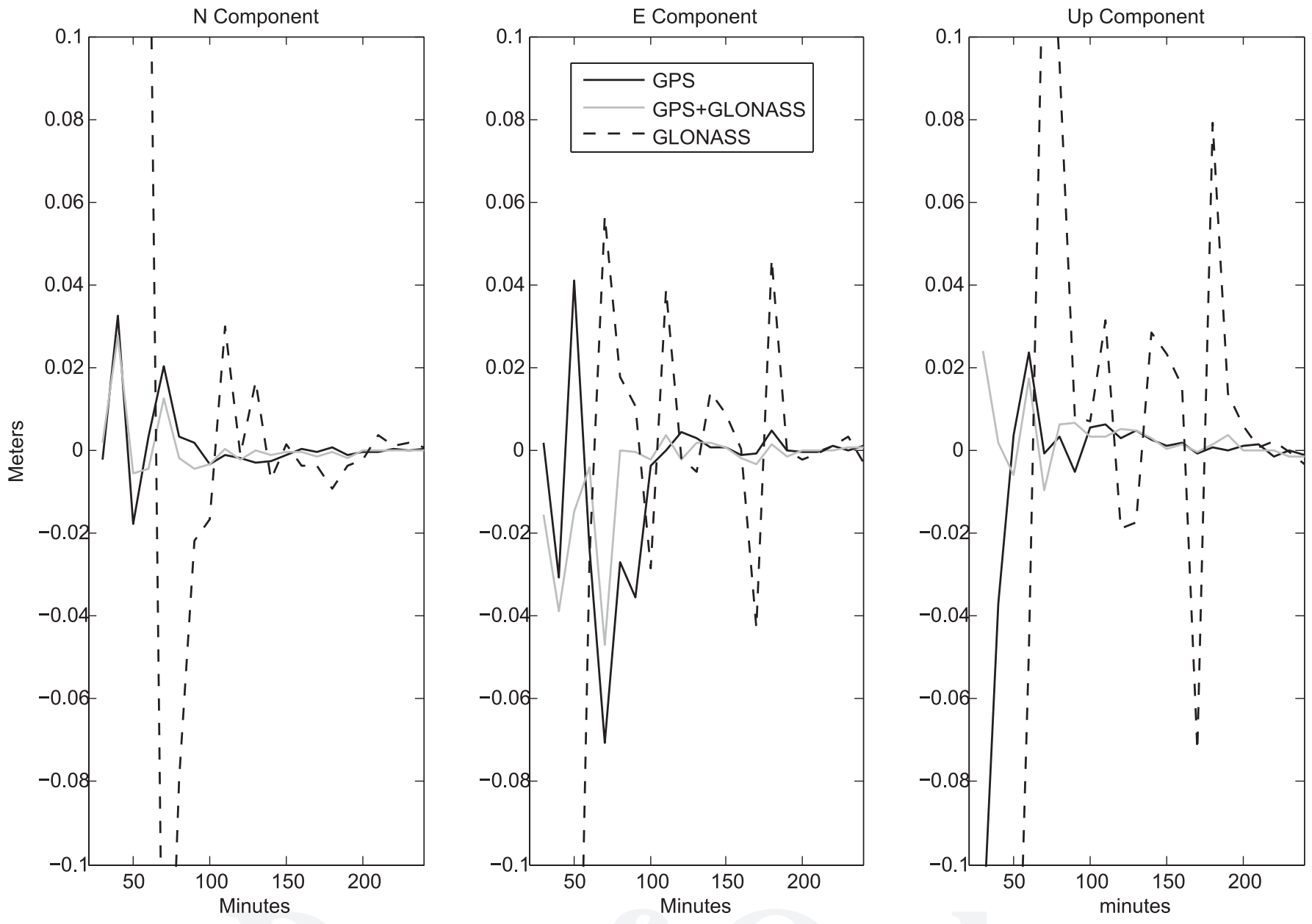

Fig. 4. Example of lower convergence time of GPS + GLONASS compared with the GPS-only or GLONASS-only solution 

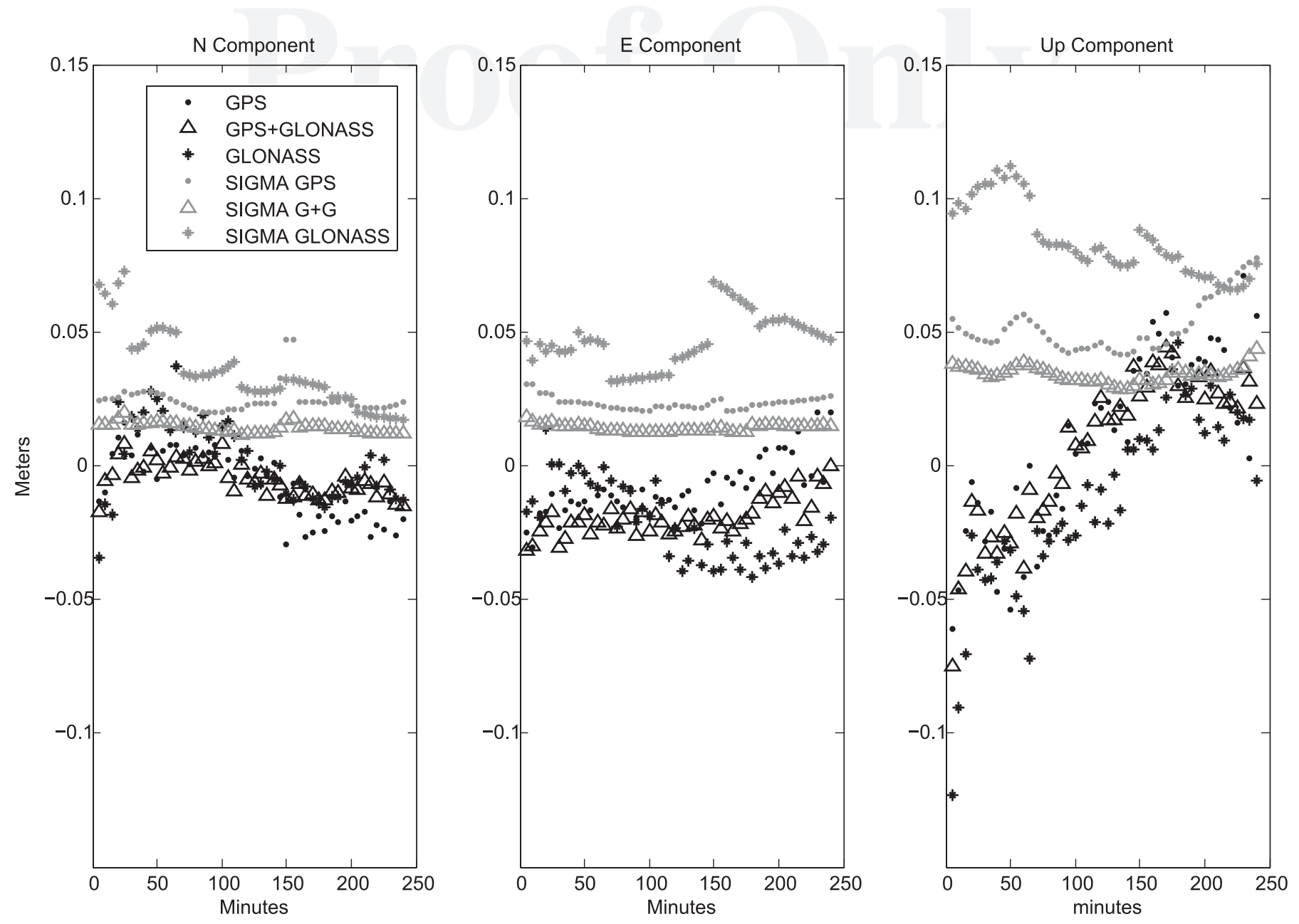

Fig. 5. Kinematic PPP bias and standard deviations in the calculation of the coordinates for GPS-only, GLONASS-only, and GPS + GLONASS solutions for the IGS MDVJ station (December 13, 2010)

\section{Static PPP Results}

The MagicGNSS software was used to process daily observation files at eight IGS stations (BRST, CONZ, KOUR, MDVJ, MTKA, NANO, REUN, and TOW2) (Fig. 1). The properties and locations of the selected receivers in the IGS network are listed in Table 1. The stations were selected based on their location to provide a balanced geographical sample capable of providing various satellite geometries of GPS and GLONASS observables. For the first $4 \mathrm{~h}$ of Day 33 (February 2), Day 211 (July 30), and Day 347 (December 13) of 2010, dual-frequency phase and code data recorded at 30-s intervals were processed and compared using GPS-only, GLONASS-only, and GPS + GLONASS constellations.

The antennas were in a location with a clear view of the sky; therefore, no obstructed satellite signal or multipath effects were expected. An improvement in the satellite geometry from the GPS-only or GLONASS-only solution compared with the GPS + GLONASS solution was computed using the geometric dilution of precision (PDOP), where a mean improvement of $27 \%$ was found for the GPS + GLONASS constellation compared with the GPS-only constellation and $80 \%$ for the comparison with the GLONASS-only constellation. As an example, this improvement in the satellite geometry can be seen in Figs. 2 and 3, where Fig. 2 presents a sky plot of the GPS and GLONASS constellations for the MDVJ station for December 13 during the $4 \mathrm{~h}$ of observation, and Fig. 3 is the associated PDOP and number of satellites for GPS-only, GLONASS-only, and GPS +
Table 4. Mean RMS of Kinematic PPP Measurements Residuals

\begin{tabular}{lcc}
\hline & $\begin{array}{c}\text { Mean RMS of code } \\
\text { residuals }(\mathrm{m})\end{array}$ & $\begin{array}{c}\text { Mean RMS of phase } \\
\text { residuals }(\mathrm{m})\end{array}$ \\
\hline GPS only & 0.280 & 0.005 \\
GLONASS only & 0.280 & 0.004 \\
GPS + GLONASS & 0.420 & 0.007 \\
\hline
\end{tabular}

Table 5. Statistical Resume of the Kinematic PPP Bias for the IGS Stations

\begin{tabular}{lccccccc}
\hline & \multicolumn{3}{c}{ GPS only $(\mathrm{m})$} & & \multicolumn{3}{c}{ GPS + GLONASS (m) } \\
\cline { 2 - 4 } Mean value & North & East & Up & & North & East & Up \\
\hline RMS & 0.036 & 0.042 & 0.113 & & 0.029 & 0.031 & 0.069 \\
Standard deviation & 0.032 & 0.031 & 0.099 & & 0.026 & 0.028 & 0.063 \\
Range & 0.177 & 0.160 & 0.675 & & 0.166 & 0.157 & 0.341 \\
\hline
\end{tabular}

GLONASS constellations. The convergence of the PPP static technique has been studied by comparing the results of stacking observations with 10-min intervals for every station during the three days of the study with the mean weekly IGS coordinates as a reference. Thus, a total of 576 GPS or GLONASS solutions and 576 GPS + GLONASS solutions were compared analyzed.

Table 2 presents the mean RMS residuals for the code and phase observations, showing the precision of the raw data in the static 
determination. Table 3 summarizes the mean convergence time for GPS-only, GLONASS-only, and GPS + GLONASS in the north $(\mathrm{N})$, east (E), and up (Up) components. The results are divided into rows, in which the first one is the mean convergence time required to reach an accuracy level of $1 \mathrm{~cm}$ and the second is the convergence time to reach an accuracy level of $10 \mathrm{~cm}$. As mean global values in

Table 6. Percentages of Solutions with Better RMS, Standard Deviation, and Range for GPS-only, GPS + GLONASS, and Equivalent Values in the Kinematic PPP Research at IGS Sites

\begin{tabular}{lcc}
\hline $\begin{array}{l}\text { Equivalent value for } \\
\text { GPS and } \mathrm{G}+\mathrm{G}\end{array}$ & $\begin{array}{c}\text { Better value for } \\
\text { GPS only }\end{array}$ & $\begin{array}{c}\text { Better value for } \\
\mathrm{G}+\mathrm{G}\end{array}$ \\
\hline $43 \%$ & $16 \%$ & $41 \%$ \\
\hline
\end{tabular}

Note: $\mathrm{G}+\mathrm{G}=\mathrm{GPS}+$ GLONASS constellation.

Table 7. Statistical Resume of the Kinematic PPP Bias for the 11 IGS Stations Where the GLONASS-Only Solution Has Been Obtained

\begin{tabular}{|c|c|c|c|c|c|c|c|c|c|}
\hline \multirow{2}{*}{$\begin{array}{l}\text { Mean } \\
\text { value }\end{array}$} & \multicolumn{3}{|c|}{ GPS only (m) } & \multicolumn{3}{|c|}{$\begin{array}{l}\text { GLONASS } \\
\text { only (m) }\end{array}$} & \multicolumn{3}{|c|}{$\begin{array}{c}\text { GPS + } \\
\text { GLONASS }(m)\end{array}$} \\
\hline & North & East & Up & North & East & Up & North & East & Up \\
\hline RMS & 0.014 & 0.015 & 0.032 & 0.040 & 0.044 & 0.081 & 0.013 & 0.012 & 0.026 \\
\hline $\begin{array}{l}\text { Standard } \\
\text { deviation }\end{array}$ & 0.010 & 0.009 & 0.024 & 0.027 & 0.025 & 0.052 & 0.009 & 0.007 & 0.021 \\
\hline Range & 0.043 & 0.044 & 0.105 & 0.121 & 0.105 & 0.264 & 0.042 & 0.035 & 0.101 \\
\hline
\end{tabular}

this study, the GPS + GLONASS solution used $20 \%$ less time to converge to a 1-cm accuracy level than the GPS-only solution and $50 \%$ less time than the GLONASS-only solution. These percentages were similar for the north, east, and up components. Moreover, the GPS + GLONASS solution used $13 \%$ less time to converge to a 10-cm accuracy level than the GPS-only solution and $57 \%$ less time than the GLONASS-only solution. Again, these percentages were similar for the north, east, and up components.

A deep analysis of the results, showed that $50 \%$ of the solutions (including the north, east, and up components) converged to a $1-\mathrm{cm}$ accuracy level using less time for the GPS + GLONASS configuration in comparison with the GPS-only configuration (Fig. 4 is an example), $21 \%$ of the solutions required the same approximate time, and the other $29 \%$ of the solutions presented less convergence time in the GPS-only than in the GPS + GLONASS solution. In the case of the convergence time required to reach an accuracy level of $10 \mathrm{~cm}$, the aforementioned percentages were 68,28 , and $4 \%$, respectively. Only three cases were found in which the GLONASS-only solution presented less convergence time than the GPS-only solution [the up component of the CONZ station (December 13, 2010) and REUN station (December 13, 2010) and the north component of the KOUR station (December 13, 2010)], and only one presented less convergence time than the GPS + GLONASS solution [the up component of the MDVJ station (February 2010)]. Finally, no clear $\mathbf{8}$ relationship between the PDOP improvement as a result of an increasing number of satellites in the GPS + GLONASS configuration and less convergence time was found.

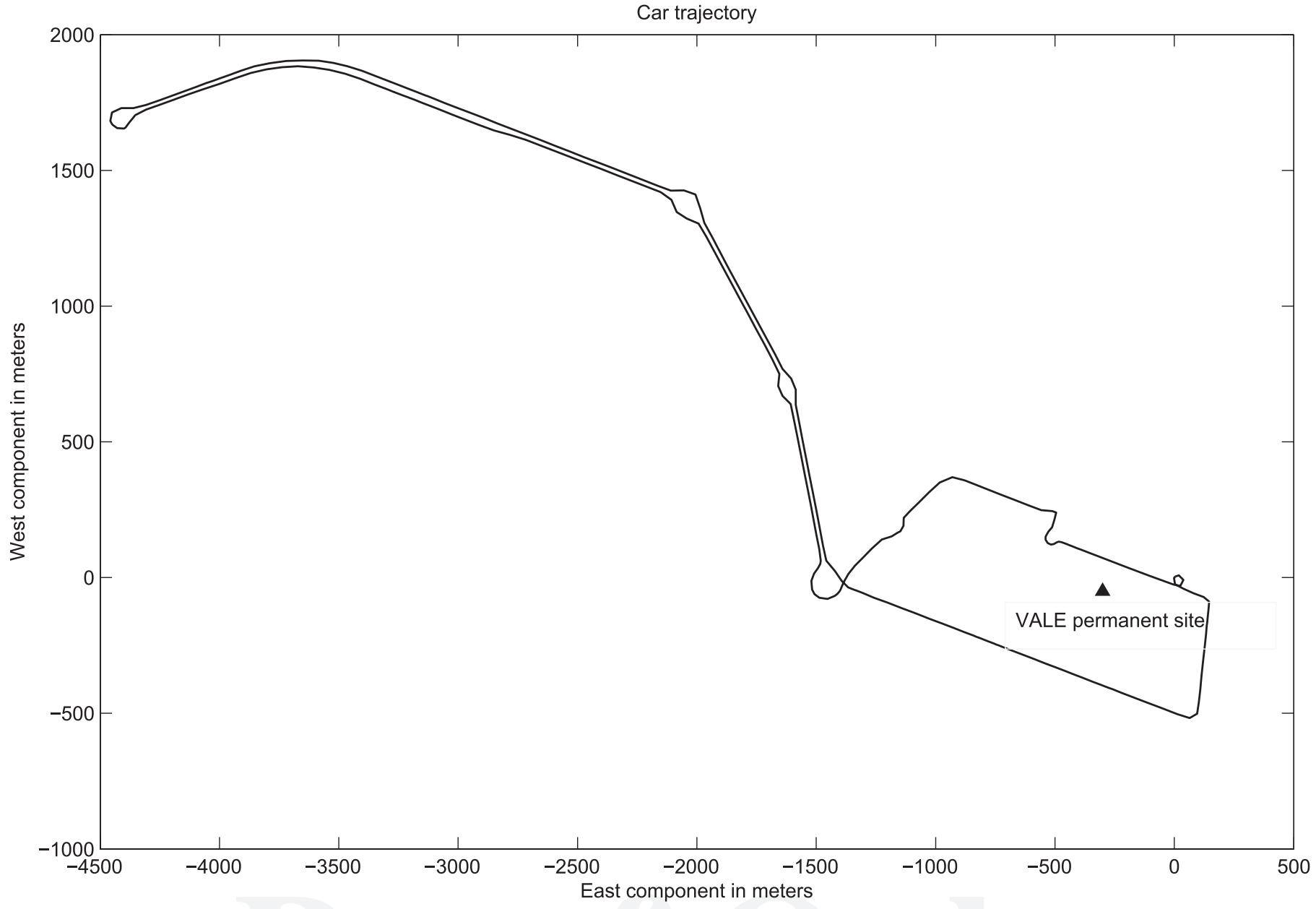

Fig. 6. Car trajectory used for the kinematic analysis 

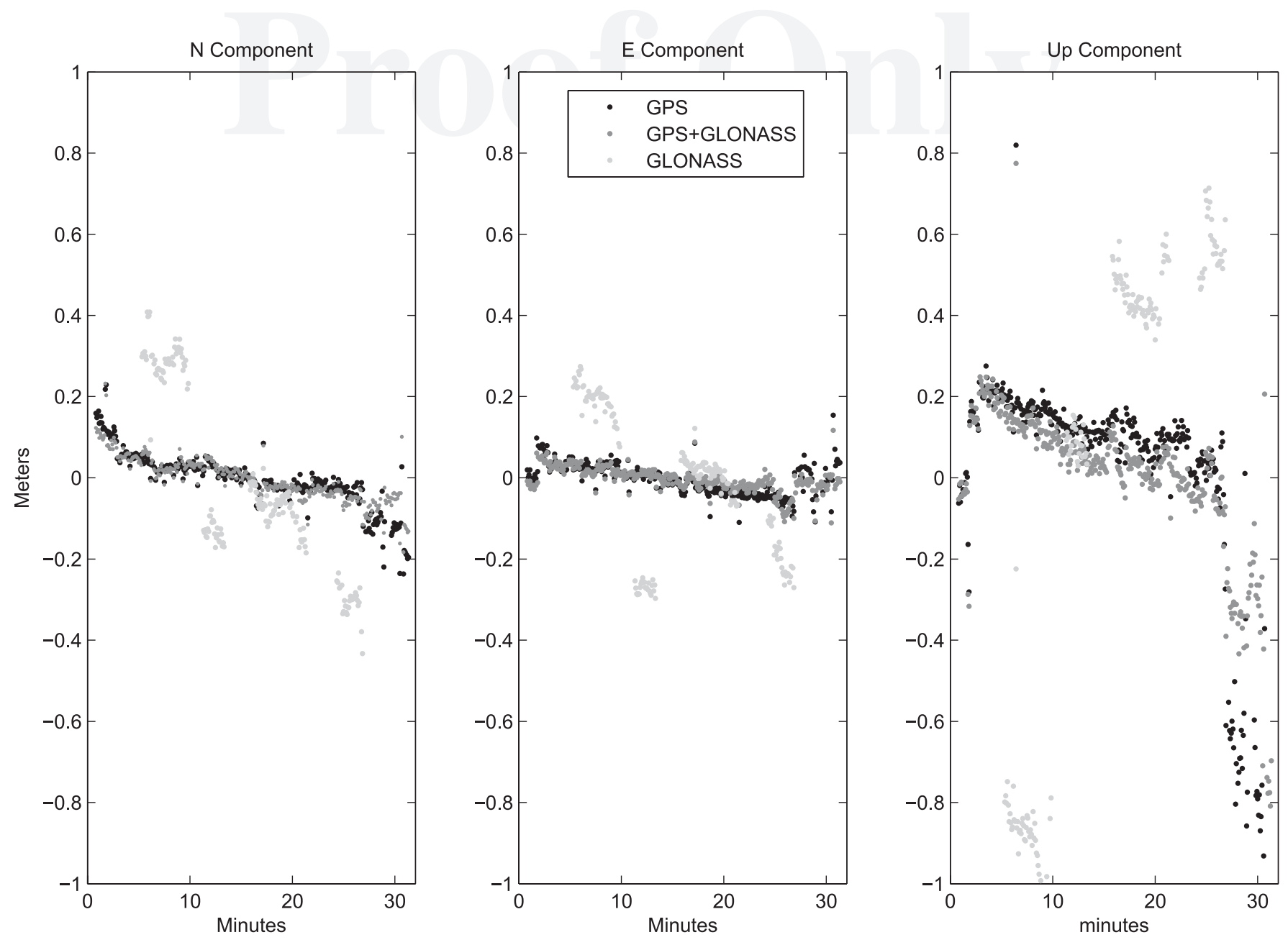

Fig. 7. Kinematic PPP bias using GPS only, GLONASS only, and GPS + GLONASS for the car trajectory

These results indicate that the GPS + GLONASS solution does not present better results than the GPS-only solution in all of the cases (this result can be found in some of the papers presented in the introduction). The explanation is related to the differences in the design of the GPS and GLONASS satellites. First, the GLONASS satellites have a cesium-based (Cs) frequency standard and will consequently have a slightly worse short-time stability than rubidium-based $(\mathrm{Rb})$ satellites (e.g., all of the GPS satellites of Block IIR, and approximately $50 \%$ of the GPS satellites of the Blocks II and IIA) (Hofmann-Wellenhof et al. 2008). Short-time frequency instability leads to increased errors of interpolated satellite clock corrections, yielding increased noise in the corrected code and phase observations (Kjorsvik et al. 2009), and thus limiting the impact on the parameter estimates and their precision. Second, while GPS signals are modulations of the same carriers, L1 and L2, for all of the satellites, the GLONASS carrier frequencies depend on the emitting channel. There are 12 channels for the 21 satellites. Because various L1 and L2 frequencies are used by the various GLONASS satellites, the receiver hardware delays are different for the various frequency channels. In addition, these biases vary considerably for receivers from various manufacturers (Wanninger 2012). Therefore, when processing the RINEX files, the additional GLONASS satellites increase the number of observations; however, the introduction of the GLONASS data also considerably increases the number of parameters (GLONASS ambiguities and intersystem hardware delays) to be estimated. Consequently, no significant improvement in terms of formal errors can be expected from adding the
GLONASS data to GPS (Bruyninx 2007). Therefore, the expected improvement of the results using the complete GPS + GLONASS system rather than GPS-only system could not be attained as a result of the variability of the GLONASS code and phase observations, which are generally larger than the GPS and the introduction of interchannel biases for GLONASS frequencies and intersystem biases (Hefty et al. 2010; Hefty and Gerhatova 2011).

\section{Kinematic PPP Results}

The kinematic configuration should be analyzed to complete the case study. It is highlighted that only the solutions of the postprocess are compared and analyzed; the fact that the postprocessing methodologies are different for the static and kinematic cases is not considered here. In addition, kinematic PPP will be the best choice for checking the performance of the GLONASS constellation in zones where the satellite signal may be partially obstructed, resulting in the limit case where no PPP solution using the GPS-only or GLONASS-only configuration can form as a result of the lack of satellites but GPS + GLONASS configuration can provide results.

\section{Kinematic Solutions at Fixed Sites}

The GNSS observations from the eight permanent IGS stations used in the static PPP research were used to test and evaluate the GPS + GLONASS kinematic PPP. These static data were processed using 

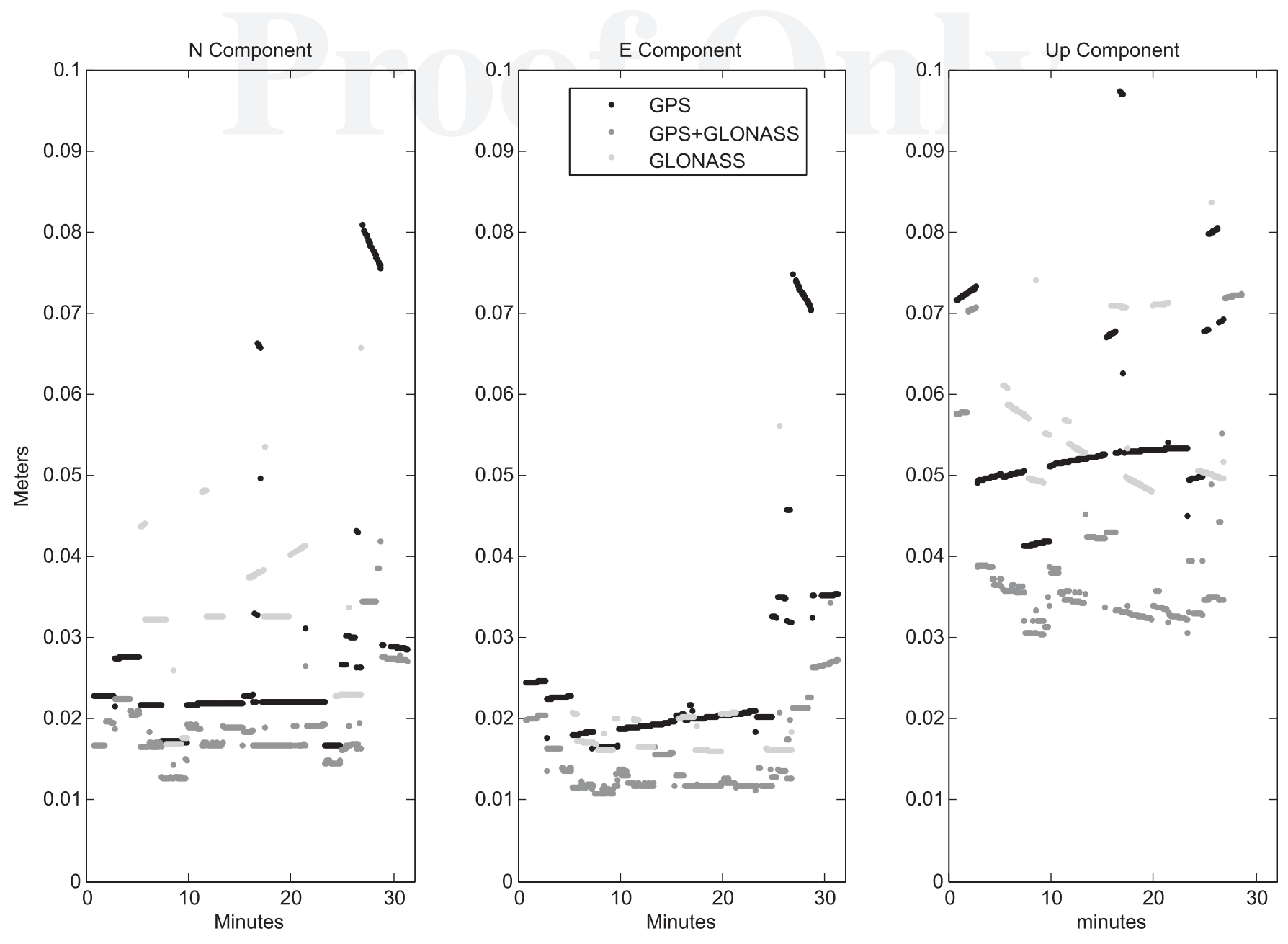

Fig. 8. Standard deviations in the calculation of the coordinates of Fig. 7

Table 8. Statistical Resume of the Kinematic PPP Bias for the Car Trajectory

\begin{tabular}{|c|c|c|c|c|c|c|c|c|c|}
\hline \multirow{2}{*}{$\begin{array}{l}\text { Mean } \\
\text { value }\end{array}$} & \multicolumn{3}{|c|}{ GPS only (m) } & \multicolumn{3}{|c|}{$\begin{array}{c}\text { GLONASS } \\
\text { only }(\mathrm{m})\end{array}$} & \multicolumn{3}{|c|}{$\begin{array}{c}\text { GPS + } \\
\text { GLONASS (m) }\end{array}$} \\
\hline & North & East & Up & North & East & Up & North & East & Up \\
\hline RMS & 0.552 & 0.646 & 0.824 & 1.652 & 2.124 & 2.132 & 0.409 & 0.891 & 0.984 \\
\hline $\begin{array}{l}\text { Standard } \\
\text { deviation }\end{array}$ & 0.090 & 0.082 & 0.332 & 0.244 & 0.210 & 0.622 & 0.080 & 0.077 & 0.190 \\
\hline Range & 1.366 & 1.480 & 2.603 & 1.816 & 1.835 & 2.772 & 1.306 & 1.464 & 1.892 \\
\hline
\end{tabular}

results. Table 5 presents the values for this statistical information, where the better performance of the GPS + GLONASS solution in comparison with the GPS-only solution can be seen; especially in the up component, where a $40 \%$ reduction can be found in the RMS and standard deviation and a 50\% reduction in the range. As in the static case, a deep analysis of the results showed that not all the GPS + GLONASS solutions presented a lower bias than the GPS-only solutions. Table 6 presents the percentage of kinematic PPP solutions with a lower mean RMS, standard deviation, and range using GPS + GLONASS in comparison with GPS only. This percentage is $41 \%$; however, $16 \%$ of the observations still have a lower mean RMS, standard deviation, and range for the GPS-only solution than the GPS + GLONASS solution. These percentages were computed for the eight permanent stations on the three days under study by taking into account the north, east, and up components.

To consider all the possible cases, the GLONASS-only solution was also considered. The GLONASS-only results were obtained only for 11 observation files because of the low number of GLONASS satellites in the other sessions and as a result of the inclusion of the interchannel bias as a new parameter to be adjusted, which generates no GLONASS-only solution with MagicGNSS in the kinematic mode in some cases (Alvaro Mozo, private communication). As in Table 5, Table 7 presents the mean values for the statistical information (mean RMS, standard deviation, and range) based on the coordinate bias (comparison between epoch-by-epoch kinematic PPP solution and the weekly IGS coordinates) for the stations where the GLONASS-only solution was obtained. As in 


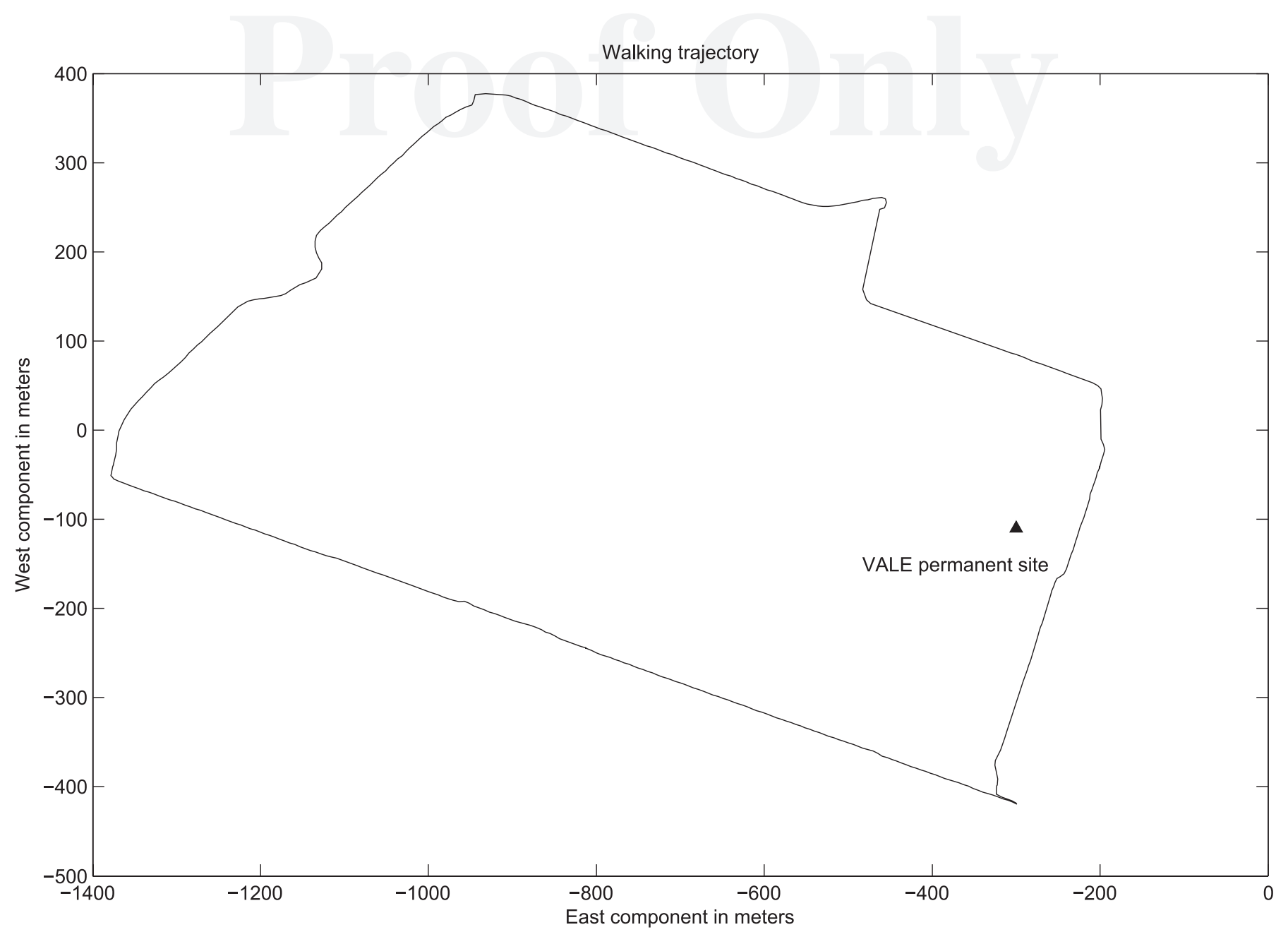

Fig. 9. Walking trajectory used for the kinematic analysis

Table 5, better performance was obtained for the GPS + GLONASS solution. Finally, GLONASS-only solution was never better than the GPS + GLONASS solution and was only better than GPS-only solution in the east component of the NANO station (July, 30, 2010) and the BRST station (December 13, 2010).

The PDOP evolution and the number of GPS and GPS + GLONASS satellites are presented in Fig. 3. If the PDOP evolution with the evolution of the kinematic bias of the results and the evolution of the standard deviation of the coordinate solution are compared, no clear correlation is found. Thus, the improvement in the geometry of the combined constellation in comparison with the GPS-only constellation does not mean a direct improvement in the kinematic PPP solution or in the standard deviation of this solution, as was found in the static case.

\section{Testing in the Kinematic Environment}

Kinematic PPP is vulnerable to data quality issues. Kinematic files are clearly noisier than IGS data sets from reference stations. Such kinematic observation data represent a more realistic scenario than the IGS data sets because a GNSS antenna mounted on a vehicle is strongly susceptible to multipath problems and signal loss as a result of vehicle dynamics and obstructions (for example, in an urban canyon environment). Such signal loss is currently the main problem with kinematic PPP use because the system must be reinitialized to resolve ambiguities. In the two subsequent sections, two tests are used to compare GPS-only, GLONASS-only, and GPS + GLONASS kinematic PPP in a kinematic environment.

\section{Car Trajectory}

On February 28, 2011, GNSS data were collected at 5-s intervals for a car trajectory analysis in the environs of the Technical University of Valencia (Fig. 6). The streets are wide enough to allow a strong GNSS signal. In addition to the dual-frequency GPS + GLONASS receiver in the car (Trimble R8 with TRMR8_GNSS antenna), there was another dual-frequency GPS + GLONASS receiver (Trimble NETRS with TRM29659.00 antenna) at a fixed, precisely known, location [the permanent International Association of the Geodesy Reference Frame subcommission for Europe (EUREF) site VALE]. The fixed site and the rover were never more than $5 \mathrm{~km}$ from each other. Thus, it was possible to obtain precise short baseline solutions for the rover receiver (mean horizontal deviation under $2 \mathrm{~cm}$ for planimetric coordinates and under $3 \mathrm{~cm}$ for the vertical coordinate). The resulting relative trajectory was used as the real trajectory to which the kinematic PPP solutions were compared with the obtain coordinate bias indicated in Fig. 7. The standard deviation in the calculation of the coordinates can be seen in Fig. 8 .

Table 8 presents the mean values for the statistical information (RMS, standard deviation, and range) of the coordinate bias for the GPS-only, GLONASS-only, and GPS + GLONASS solutions. A slight improvement based on the standard deviation and range was found for the north and east components of the GPS + GLONASS 

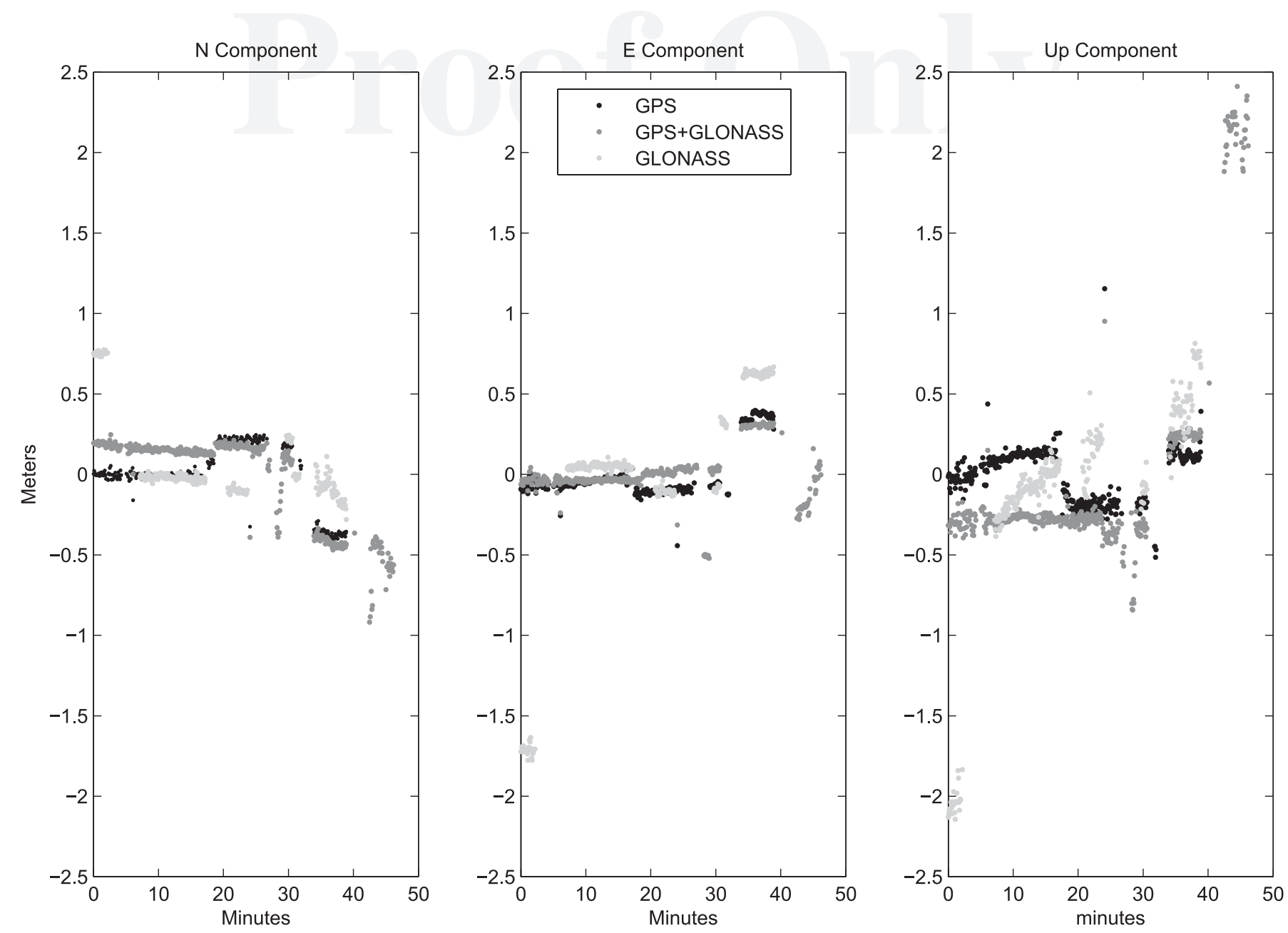

Fig. 10. Kinematic PPP bias using GPS only, GLONASS only, and GPS + GLONASS for the walking trajectory

solution in comparison with the GPS-only solution, and there was a reduction of $42 \%$ in the standard deviation and $27 \%$ in the range for the up component. The mean PDOP was reduced by $21 \%$ for the GPS + GLONASS solution in comparison with the GPS-only solution. In addition, the GLONASS-only solution was never better than the GPS-only solution or the GPS + GLONASS solution.

The final part of the trajectory presents the major bias values in the GPS-only, GLONASS-only, and GPS + GLONASS solutions (the northeast part in Fig. 6) because of the building obstructions on the campus. This is an example of the sensitivity of PPP to interruptions in signal tracking and data gaps, which significantly influence the accuracy of kinematic PPP; that is, the momentary loss of the satellite signal not only produces no PPP solution. However, in the case of a solution it presents a higher bias and standard deviation in the calculation of the coordinates. Finally, only $2 \%$ of the solutions were not found in the GPS-only solution in comparison with the GPS + GLONASS solution because of the building obstructions of the satellite signal.

\section{Walking Trajectory}

The final test was conducted on February 18, 2011. In this test, a walking trajectory around the campus of the Technical University of Valencia was analyzed (Fig. 9). The data were recorded at 5-s intervals using the same GNSS dual-frequency receiver as in the car trajectory, and - as in the analysis of the car trajectory - the data from the VALE permanent station were used to obtain the real trajectory (with the same precision level) to be compared with the kinematic PPP solutions to obtain the coordinate bias to analyze. In the GLONASS-only and GPS + GLONASS solutions, two GLONASS satellites (R6 and R21) were manually excluded before processing because of the high RMS on the code residual $(70-80 \mathrm{~m})$; this procedure can also be found in Kjorsvik et al. (2009). Fig. 10 presents the coordinate bias for the GPS-only, GLONASS-only, and GPS + GLONASS solutions without the R6 and R21 satellites. The standard deviation in the calculation of the coordinates can be seen in Fig. 11 .

Table 9 presents the mean values for the statistical information (RMS, standard deviation, and range) of the coordinate bias for the GPS-only, GLONASS-only, and GPS + GLONASS solutions for the first $30 \mathrm{~min}$ of the walking trajectory (before multiple signal losses). As in the car trajectory, a slight improvement can be found for the east component of the GPS + GLONASS solution in comparison with the GPS-only solution, and reductions of 62 and $44 \%$ in the standard deviation for the north and up components, respectively, were obtained. The mean PDOP was reduced by $31 \%$ for the GPS + GLONASS solution in comparison with the GPS-only solution.

In addition, the GLONASS-only solution was never better than the GPS-only solution or the GPS + GLONASS solution. However, as can be seen in Fig. 10, this is the test that produced the most significant data gaps for GPS and GLONASS signals; $30 \%$ of the code or phase observations were not processed by the MagicGNSS software with none of the GPS-only, GLONASS-only, or GPS + GLONASS constellations. Most of the issues arose in the final part of the trajectory (in exactly the same zone in which the data gaps 

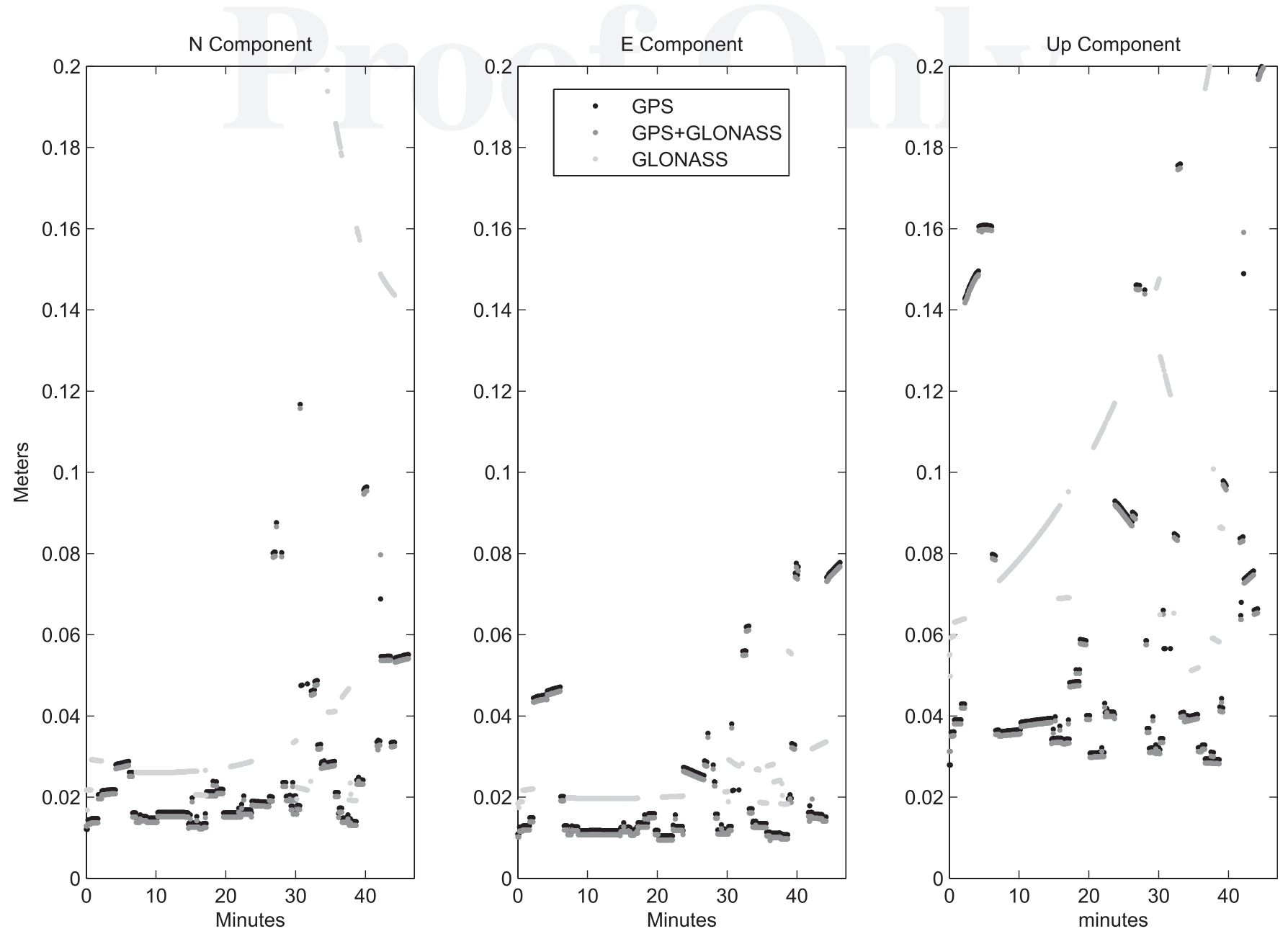

Fig. 11. Standard deviation in the calculation of the coordinates of Fig. 10

Table 9. Statistical Resume of the Kinematic PPP Bias for the Walking Trajectory

\begin{tabular}{|c|c|c|c|c|c|c|c|c|c|}
\hline \multirow{2}{*}{$\begin{array}{l}\text { Mean } \\
\text { value }\end{array}$} & \multicolumn{3}{|c|}{ GPS only (m) } & \multicolumn{3}{|c|}{$\begin{array}{c}\text { GLONASS } \\
\text { only }(\mathrm{m})\end{array}$} & \multicolumn{3}{|c|}{$\begin{array}{c}\text { GPS + } \\
\text { GLONASS (m) }\end{array}$} \\
\hline & North & East & Up & North & East & Up & North & East & Up \\
\hline RMS & 0.125 & 0.198 & 0.679 & 1.039 & 0.969 & 0.710 & 0.220 & 0.763 & 0.095 \\
\hline $\begin{array}{l}\text { Standard } \\
\text { deviation }\end{array}$ & 0.101 & 0.045 & 0.157 & 0.277 & 0.604 & 0.706 & 0.045 & 0.037 & 0.088 \\
\hline Range & 0.570 & 0.487 & 1.431 & 0.902 & 1.884 & 2.649 & 0.538 & 0.369 & 1.397 \\
\hline
\end{tabular}

occurred in the car trajectory because of building obstructions). For that portion of the trajectory, continuous jumps in the solutions can be found. Finally, only $7 \%$ of the solutions were not found in the GPS-only solution in comparison with the GPS + GLONASS solution because of the building obstructions of the satellite signal, resulting in no solution with the GPS-only constellation mostly in the final part of the trajectory (Fig. 10).

\section{Conclusions}

This study aimed at testing the performance of a dual-frequency GPS + GLONASS PPP solution in both static and kinematic environments in comparison with GPS-only and GLONASS-only solutions. It has been shown that the addition of the GLONASS constellation improved the satellite availability and geometry by more than $20 \%$. This improvement allows for precise surveying in urban areas or when the satellite signal is partially obstructed. However, this improvement in the geometry of the combined constellation in comparison with the GPS-only or GLONASS-only constellation does not necessarily mean an improvement in the static or kinematic PPP solution or in the standard deviation of the solution.

The main conclusion of the static study is that the addition of the GLONASS constellation improves the convergence of static PPP by $20 \%$ as a mean value for a $1-\mathrm{cm}$ accuracy level and by $13 \%$ for a $10-\mathrm{cm}$ accuracy level. However, if the total convergence time is considered, the GPS-only solution presents a better convergence time in $29 \%$ of the cases in comparison with the GPS + GLONASS results. Thus, the GPS + GLONASS results do not present better results than the GPS-only solution in all of the static cases.

The mean kinematic results from the permanent IGS sites showed that a $40 \%$ reduction can be found in the mean RMS and standard deviation of the GPS + GLONASS results in comparison with the GPS-only results and $50 \%$ in the range. However, $16 \%$ of the solutions presented a lower mean RMS, standard deviation, and range for the GPS-only solution in comparison with the GPS + GLONASS results. Thus, the GPS + GLONASS results do not present better results than the GPS-only solution in all of the kinematic cases using the IGS permanent stations. The kinematic results from the kinematic environment (car and walking trajectories) presented better accuracy with the GPS + GLONASS solution than the GPS-only solution. 
Finally, the GLONASS-only solutions were not as accurate as the GPS-only or GPS + GLONASS solutions in either the static or kinematic mode. Thus, in this case study, the GPS + GLONASS solution was noticeably more accurate than the GPS-only solution if the mean results in the static and kinematic solutions for the IGS sites are considered, and more accurate and robust in all the kinematic environment cases (here, robust means that the GPS + GLONASS kinematic PPP can produce a solution when signal tracking interruptions are present). Two main factors are expected to contribute to further improvements; i.e., the ongoing and planned next generation of GLONASS satellites (GLONASS-K) and further improvements in the precision of the GPS and GLONASS orbit and clock products.

\section{Acknowledgments}

This research is supported by Spanish Science and Innovation Directorate Project No. AYA2010-18706. The authors greatly appreciate the efforts of the IGS, Analysis and Data Centers, and tracking station managers for generating high-quality data and products and for making them available to the GNSS community in a timely and reliable way. The authors would like to thank Alvaro Mozo and Ricardo Píriz from GMV Aerospace for the free use of the online software MagicGNSS and their valuable comments on how MagicGNSS works. The three anonymous reviewers are kindly acknowledged for their contribution to the improvement of the paper with their valuable comments and suggestions.

\section{References}

Alcay, S., Inal, C., Yigit, C. O., and Yetkin, M. (2012). "Comparing GLONASS-only with GPS-only and hybrid positioning in various lenght of baselines." Acta Geod. Geoph. Hung., 47(1), 1-12.

Azab, M., El-Rabbany, A., Shoukry, M. N, and Khalil, R. (2011). "Precise point positioning using combined GPS/GLONASS measurements." Proc., FIG Working Week 2001, Bridging the Gap between Cultures, Marrakech, Marocco.

Bisnath, S. N., Beran, T., and Langley, R. B. (2002). "Precise platform positioning with a single GPS receiver." GPS World, 13(4), 42-49.

Bruyninx, C. (2007). "Comparing GPS-only with GPS + GLONASS positioning in a regional permanent GNSS network." GPS Solutions, 11(2), 97-106.

Cai, C., and Gao, Y. (2007). "Precise point positioning using combined GPS and GLONASS observations.” J. Global Positioning Syst., 6(1), $13-22$.

Chen, K. (2004). "Real-time precise point positioning and its potential application." Proc., ION GNSS 17th Int. Technical Meeting of the Satellite Division, Long Beach, CA.

Chen, W., Hu, C., Gao, S., Chen, Y., and Ding, X. (2009). "Error correction models and their effects on GPS precise point positioning." Surv. Rev., 41(313), 238-252.

Colombo, O. L., Sutter, A. W., and Evans, A. G. (2004). "Evaluation of precise, kinematic GPS point positioning." Proc., ION GNSS 17th Int. Technical Meeting of the Satellite Division, Long Beach, CA.

Gao, Y., and Shen, X. (2001). "Improving convergence speed of carrier phase based precise point positioning." Proc., of ION GPS 200, Salt Lake City, 1532-1539.

Gao, Y., and Shen, X. (2002). "A new method for carrier phase based precise point positioning navigation.” J. Inst. Navig., 49(2), 109-116.
Geng, J., Meng, X., Teferle, N., and Dodson, A. (2010). "Performance of precise point positioning with ambiguity resolution for 1- to 4-hour observation periods." Surv. Rev, 42(316), 155-165.

GMV Aerospace and Defence. (2010). "MagicGNSS precise point positioning by email." 〈http://magicgnss.gmv.com/ppp/〉 (Mar. 2010).

Hefty, J., and Gerhatova, L. (2011). "Specificities of GLONASS pseudorange and phase processing in the precise point positioning algorithms when combining with GPS." Proc., European General Assembly, Vienna, Austria.

Hefty, J., Gerhatova, L., and Burgan, J. (2010). "Combination of GPS and GLONASS in PPP algorithms and its effect on site coordinates determination." Proc., Journées Systèms de Référence Spatio-Temporels, New Challenges for Reference Systems and Numerical Standards in Astronomy, Paris, 200-201.

Héroux, P., et al. (2004). "Products and applications for precise point positioning-Moving towards real-time." Proc., ION GNSS 17th Int. Technical Meeting of the Satellite Division, Long Beach, CA.

Hesselbarth, A., and Wanninger, L. (2008). "Short-term stability of GNSS satellite clocks and its effects on precise point positioning." Proc., ION GNSS 21 st Int. Technical Meeting of the Satellite Division of the Institute of Navigation, Institute of Navigation, Manassas, VA, 1855-1863.

Hofmann-Wellenhof, B., Lichtenegger, H., and Wasle, E. (2008). GNSS, global navigation satellite systems: GPS, GLONASS, GALILEO \& more, Springer, New York.

Jensen, A. B. O., and Ovstedal, O. (2008). "The effect of different tropospheric models on precise point positioning in kinematic mode." Surv. Rev, 40(308), 173-187.

Kouba, J., and Héroux, P. (2001). "Precise point positioning using IGS orbit and clock products." GPS Solutions, 5(2), 12-28.

Kjorsvik, N. S., Ovstedal, O., and Gjevestad, J. G. O. (2009). "Kinematic precise point positioning during marginal satellite availability." Proc., Int. Association of Geodesy Symposia 133: Observing Our Changing Earth, 691-699.

Martín, A., Anquela, A. B., Berné, J. L., and Sanmartín, M. (2012). "Kinematic GNSS-PPP results from various software packages and raw data configurations." Sci. Res. Essays, 7(3), 419-431.

Martín, A., Anquela, A. B., Capilla, R., and Berné, J. L. (2011). "PPP technique analysis based on time convergence, repeatability, IGS products, different software porcessing, and GPS + GLONASS constellation." J. Surv. Eng., 137(3), 99-108.

Melgard, T., Vigen, E., Orpen, O., and Ulstein, J. H. (2010). "Pulling in all signals. PPP with GPS and GLONASS: The new G2." GPS World, 21(3), 28-35.

National Geophysical Data Center (NGDC). (2010). "Global self-consistent, hierarchical, high-resolution shoreline database (GSHHS)." 〈http://www. ngdc.noaa.gov/mgg/shorelines/gshhs.html (Feb. 2010).

Píriz, R., Calle, D., Mozo, A., Navarro, P., Rodríguez, D., and Tobías, G. (2009). "Orbits and clocks for GLONASS precise-point-positioning." Proc., ION GNSS 22nd Int. Technical Meeting of the SatelliteDivision of the Institute of Navigation, Institute of Navigation, Manassas, VA.

Píriz, R., Mozo, A., Navarro, P., and Rodríguez, D. (2008). "MagicGNSS: Precise GNSS products out of the box." Proc., ION GNSS 21st Int. Technical Meeting of the Satellite Division of the Institute of Navigation, Institute of Navigation, Manassas, VA, 1242-1251.

Wanninger, L. (2012). "Carrier-phase inter-frequency biases of GLONASS receivers." J. Geodesy, 86(2), 139-148.

Zumberge, J. F., Heflin, M. B., Jefferson, D. C., Watkins, M. M., and Webb, F. H. (1997). "Precise point positioning for the efficient and robust analysis of GPS data from large networks." J. Geophys. Res., 102(B3), 5005-5018. 


\section{AUTHOR QUERIES}

\section{AUTHOR PLEASE ANSWER ALL QUERIES}

Q: 1_Please clarify the use of "+" in the title; can this be changed to "and"?

Q: 2_Please verify "A. Martín” is correct and not "A. Martín Furones."

Q: 3_AU: Please check our changes to the English throughout to make sure your meaning has been preserved.

Q: 4_Is GLONASS the combination of GPS and GNSS? Both GLONASS and GNSS seem to expand to global navigation satellite system. Please clarify which is, or if both are, correct.

Q: 5_Please verify the formatting of the univerisity address is correct for each affiliation. Specifically, "ClCamino de Vera s/n."

Q: 6_AU: In the affiliations please supply the title/position for each author.

Q: 7_AU: Please spell out acronym ITRF.

Q: 8_AU: For the MDVJ station, what was the day in February 2010?

Q: 9_If this is an acronym, please expand.

Q: 10_AU: Please provide the name and location of the publisher for the reference "Azab et al. (2011)." If there is no "publisher," then please provide the name and location of the sponsor.

Q: 11_AU: Please provide the name and location of the publisher for the reference "Chen (2004)." If there is no "publisher," then please provide the name and location of the sponsor.

Q: 12_AU: Please provide the name and location of the publisher for the reference "Colombo et al. (2004)." If there is no "publisher," then please provide the name and location of the sponsor.

Q: 13_AU: Please provide the name and location of the publisher for the reference "Gao and Shen (2001)." If there is no "publisher," then please provide the name and location of the sponsor.

Q: 14_AU: Please provide the name and location of the publisher for the reference "Hefty and Gerhatova (2011)." If there is no "publisher," then please provide the name and location of the sponsor.

Q: 15_AU: Please provide the name and location of the publisher for the reference "Hefty et al. (2010)." If there is no "publisher," then please provide the name and location of the sponsor.

Q: 16_AU: Please provide the name and location of the publisher for the reference "Heroux et al. (2004)." If there is no "publisher," then please provide the name and location of the sponsor.

Q: 17_AU: Please provide the name and location of the publisher for the reference "Kjorsvik et al. (2009)." If there is no "publisher," then please provide the name and location of the sponsor.

Q: 18_If available, please provide the full date of access (mm/dd/yyyy) in NGDC 2010.

Q: 19_AU: In Table 2, please supply a heading for column 1.

Q: 20_AU: In Table 4, please supply a heading for column 1. 